16. Серкова, Н. И. Политкорректные эвфемизмы русского и английского языков в современной лексикографической практике / Социальные и гуманитарные науки на Дальнем Востоке. Хабаровск: Изд-во ДВГУПС. - 2015. - №2. - С.23-31.

17. Серкова, Н.И. Политкорректная эвфемистическая лексика как социокультурный код нации / ВОСТОК-ЗАПАД: ВЗАИМОДЕЙСТВИЕ ЯЗЫКОВ И КУЛЬТУР Сборник материалов III Международной научно-практической конференции. - 2015. - С.107-110.

18. Тер-Минасова, С.Г. Язык и межкультурная коммуникация. - М.: Слово, 2000. - 624c.

19. Andrews, E. Cultural Sensitivity and Political Correctness: The Linguistic Problem of Naming / American Speech, Vol. 71, No. 4 (Winter), 1996. - P. 389-404.

20. Beecher Stowe, Harriet / Uncle Tom's Cabin, CreateSpace Independent Publishing Platform, 1852. - 419p.

21. Chandler, D. TheSapir-WhorfHypothesis, 1994: [Электронный ресурс]. - Режим доступа: http://www.aber.ac.uk/media/Documents/short/whorf.html (дата обращения: 12.09.2017)

22. Enright, D., Fair Of Speech: The Uses Of Euphemism. 1985. - 255p.

23. Holder, R. W. How Not To Say What You Mean. A Dictionary of Euphemisms / R. W. Holder. - 3rd ed. NewYork: Oxford University Press Inc., 2002. - 501p.

24. Warren, B. What Euphemisms Tell Us About the Interpretation of Words / Studia Linguistica. - N.46, No 2. -1992 . - P.128-145.

\title{
Гудкова-Кученкова А.Б., Коптякова Е.Е. Способы перевода сравнений в художественном произведении (на материале романа стивена кинга «зелёная миля» и его переводов на русский язык)
}

Сургутский Государственный Университет (Россия, Сургут)

doi:10.18411/spc-22-04-2018-20

idsp: 000001:spc-22-04-2018-20

Текст представляет собой организованную последовательность фрагментом письменного произведения законченную по своему строению и содержанию.

Согласно Комиссарову В.Н., существуют три типа текстов: технические тексты, философские и литературные тексты [7, 1999, с. 209].

Особый интерес в переводческом деле представляет художественный текст. Художественный текст - это сверхфразовое единство, характеризуемое общностью идейно-тематического содержания, и оказывающее эстетическое воздействие на читателя, охватывающее все жанровое разнообразие художественной литературы, литературной критики и публицистики $[8,2005$, с. 160]. Он характеризуется наличием многообразных средств художественной выразительности, которые в системе художественного текста несут особую эмоционально-эстетическую, экспрессивную информацию, что зачастую вызывает трудности при переводе [3, 2001, с. 156]. Одним из ярчайших средств художественной выразительности является сравнение. Сравнение - это стилистический прием, средство уподобления одного объекта другому по какимлибо признакам с целью выявлений различий или сходства, характеризирующийся использованием таких лексических единиц, как : as, such as, as if, like, seem и др.

Как объект лингвистического исследования сравнение изучалась и изучается многими лингвистами. Среди них можно выделить Н.Д. Арутюнову, А.И. Ефимова, П.П. Каминского, М.П. Ковалевой и др.

При передаче художественного произведения на другой язык переводчики применяют художественный перевод. Под художественным переводом следует понимать вид переводческой деятельности, основной задачей которого является воспроизведение на языке перевода речевого произведения, способного оказывать художественно-эстетическое воздействие на рецептор перевода, подобное воздействию, которое оказывает данное художественное произведение на исходном языке. Перевод художественных текстов считается одним из самых сложных. Ведь цель переводчика заключается в достижении определенного эстетического воздействия, передаче художественного образа, стиля автора, сохранение 
гармоничности текста, а самое главное - сохранение и передача прагматики текста (коммуникативный эффект) [7, 1999, с. 60].

Одним из наиболее интересных аспектов перевода художественных текстов является проблема передачи сравнений на воспринимающий язык. Важность изучения перевода сравнений обусловлена тем, что, для достижения коммуникативного эффекта, автору перевода необходимо адекватно передать образную информацию на переводящий язык и воссоздать стилистический эффект оригинала в переводе. А достигается это за счет умение переводчика применять различные трансформации.

В лингвистике существуют различные классификации переводческих трансформаций. Можно выделить классификации А. Д. Швейцера, Я.И. Рецкера, Миньяр-Белоручева Р.К., Комиссарова В. Н, Бархударова Л.С., Казаковой Т.А.

Для перевода стилистических средств в лингвистическом обществе используют классификацию Казаковой Т.А., которая выделяет 3 группы трансформаций: лексические, грамматические и стилистические [6, 2000, с. 104].

К лексическим трансформациям Т.А. Казакова относит транскрипцию, транслитерацию, калькирование и лексико-семантические модификации (конкретизация, генерализация, нейтрализация, эмфатизация, функциональный перевод, описательный перевод).

К грамматическим трансформациям относятся: расщепление, стяжение, конверсия, антонимический перевод, нулевой перевод, уподобление, грамматические замены и функциональные замены. А также некоторые синтаксические трансформации, такие как полный перевод и частичный перевод, который включает сокращение, расширение, перестановку и опущение.

А среди стилистических трансформаций выделяют замену словесного состава, замену образа или тропа, изъятие переносного значения и дословный перевод.

Рассматривая перевод сравнений, следует отметить понятие адекватности перевода. Адекватность - соответствие выбора языковых знаков на языке перевода тому измерению исходного текста, которое избирается в качестве основного ориентира процесса перевода. Другими словами адекватность - это соответствие текста перевода цели перевода, соответствие подлиннику по функции и оправданность выбора средств в переводе; качество переводческого решения как процесса.

Рассматривая средства художественной выразительности, в особенности сравнение, следует отметить мастера ужасов Стивена Кинга, и в частности всем известный роман «Зеленая миля». Данное произведение насыщенно множеством средств художественной выразительности, придающих произведению особую стилистическую окраску, с некоторой небрежностью диалоговой речи и мрачностью описаний.

В тексте можно выделить более 50 сравнений! А передача их на русский язык вызывает трудности у переводчиков, в связи с чем, отбор сравнений в тексте и способы их перевода на русский язык представляет особый интерес для исследования.

Для иллюстрации особенностей перевода сравнений на материале романа и его переводов Стивена Кинга «Зеленая миля» мы отобрали наиболее яркие, и характеризующие стиль автора сравнения и провели их анализ.

Рассмотрим сравнения и методы их переводов и адекватность переводов подробно.

Пример №1

\begin{tabular}{|c|c|c|}
\hline Оригинал & М.В. Опалева & В. А. Вебера \\
\hline $\begin{array}{l}\text { The man holding them sat bawling } \\
\text { up at the sky like a moonstruck } \\
\text { calf, his dark brown cheeks slicked } \\
\text { with tears, his face twisted in a } \\
\text { monstrous cramp of grief. }\end{array}$ & $\begin{array}{c}\text { Человек, держащий их, сидел и } \\
\text { выл на небо, как «помешанный } \\
\text { теленок», по его коричневым } \\
\text { щекам бежали слезы, лицо } \\
\text { исказилось чудовищной } \\
\text { гримасой горя. }\end{array}$ & $\begin{array}{c}\text { Мужчина, держащий их в руках, } \\
\text { выл, уставившись в небо, словно } \\
\text { полуночный волк, по } \\
\text { коричневым щекам катились } \\
\text { слезы, лицо перекосила гримаса } \\
\text { боли. }\end{array}$ \\
\hline
\end{tabular}


В отобранном примере мы определили сравнение - «like a moonstruck calf» , указывающее на состояние полной безысходности в ситуации , когда Джон Коффи не в силах изменить положение и вернуть девочек к жизни. Первый переводчик использует прием калькирования, обусловленный наличием в языке перевода эквивалентного лексического соответствия. Второй переводчик используют прием лексической замены, руководствуясь личным субъективным выбором, а также стилистическими особенностями русского языка. В русской литературе животным, отличающимся диким воем, считается волк. В виду того, что главное целью художественного перевода является сохранение прагматики текста и передача художественного образа, оба перевода можно считать адекватными.

Пример №2

\begin{tabular}{|c|c|c|}
\hline Оригинал & М.В. Опалева & В. А. Вебера \\
\hline $\begin{array}{c}\text { Moores had stood his ground, } \\
\text { grabbed the skatehound's wrist, and } \\
\text { had twisted it so hard that the } \\
\text { snapping bones had sounded like } \\
\text { dry twigs burning in a hot fire. }\end{array}$ & $\begin{array}{c}\text { Мурс перехватил кисть негодяя } \\
\text { и скрутил ее так, что кости } \\
\text { захрустели, словно сухие ветки }\end{array}$ & $\begin{array}{c}\text { Пурс не отступил ни на шаг, } \\
\text { которая сжимала нож, и } \\
\text { вывернул ее с такой силой, что } \\
\text { ломающиеся кости затрещали, } \\
\text { словно сухие ветки в костре. }\end{array}$ \\
\hline
\end{tabular}

В представленном примере мы рассматриваем сравнение «like dry twigs burning in a hot fire», которое автор ввел в качестве описания действий персонажа , придавая высказыванию большую экспрессивность и мрачную атмосферу. Оба переводчика применили прием опущение, избегая лексической избыточности и прием сужения значения лексической единицы, в соответствии с литературной нормой русского языка. Оба перевода можно считать адекватными.

\section{Пример №3}

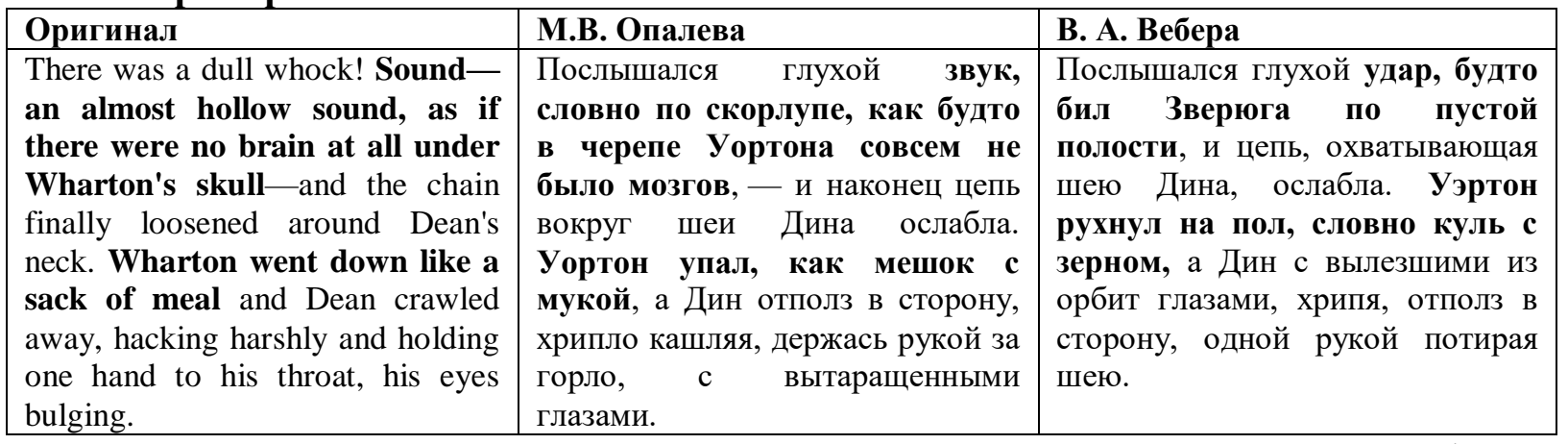

Вданномпримеремывыделяемдвасравнения - первый случай это - «Sound-an almost hollow sound, as if there were no brain at all under Wharton's skull». Ивторой «Wharton went down like a sack of meal». При передаче первого случая сравнения первый переводчик применил лексическую замену, для придания высказыванию большей образности, второй же переводчик использовал функциональную замену, обусловленную контекстом. При передаче «Wharton went down like a sack of meal» первый переводчик применил калькирование, а второй переводчик использовал лексическую замену для придания выражению большей экспрессивности. Оба перевода можно считать адекватными, поскольку прагматическая цель перевода выполнена, но второй перевод мы считаем наиболее репрезентативным, в виду его больше стилистической образности.

\section{Пример №4}

\begin{tabular}{|c|c|c|}
\hline Оригинал & М.В. Опалева & В. А. Вебера \\
\hline I was suddenly positive that & Я вдруг ясно почувствовал, что & Тут я понял, что сейчас может \\
something awful was going to & должно произойти что-то & случиться что-то ужасное, \\
happen, some- thing that would & ужасное, что-то, способное & способное полностью изменить \\
change the planned course of this & кардинально изменить & намеченный план, точно так же, \\
early morning as completely as a & запланированный ход событий, & как землетрясение меняет \\
cataclysmic earthquakecan & как внезапное землетрясение & русло реки. \\
change the course of a river & может изменить русло реки. & \\
\hline
\end{tabular}


В предложенном примере мы рассматриваем сравнение во фразе - «аs a cataclysmic earthquake can change the course of a river». При передаче сравнения на русский язык первый переводчик применил приемы лексической замены единицы cataclysmic", руководствуясь своим субъективным выбором.( в принципе эквивалент можно подобрать). Второй переводчик применил прием опущения, избегая лексической избыточности и делая предложение более лаконичным. Наиболее адекватным мы можем считать перевод М.В. Опалевой, в виду его соответствия контексту и большей стилистической образности.

Пример №5

\begin{tabular}{|c|c|c|}
\hline Оригинал & М.В. Опалева & В. А. Вебера \\
\hline $\begin{array}{c}\text { They did touch you, you know; you } \\
\text { didn't see them at their worst, } \\
\text { hammer- ing out their horrors like } \\
\text { demons at a forge }\end{array}$ & $\begin{array}{c}\text { Да, они могли вызывать } \\
\text { сочувствие, ведь мы их не } \\
\text { виели с худшей стороны, когда } \\
\text { ужасы выскакивали из них, } \\
\text { словно демоны в кузнице. }\end{array}$ & $\begin{array}{c}\text { Если видишь в осужденных что- } \\
\text { по человеческое, значит, они не } \\
\text { темной ипостаси, не дадут } \\
\text { вырваться демонам, что } \\
\text { прячутя у них в душе. }\end{array}$ \\
\hline
\end{tabular}

В представленном примере мы рассматриваем сравнение во фразе - «like demons at a forge». Данным сравнением автор хочет донести до читателя, насколько ужасны преступники прибывают на Зеленую милю. При передаче сравнения первый переводчик применил калькирование, в то время как второй переводчик использовал прием функциональной замены. Учитывая сохранение прагматики в обоих переводах, можно считать оба перевода адекватными, но первый мы будем считать наиболее репрезентативны, в виду его большей стилистической экспрессивности.

Таким образом, мы можем заключить, что перевод сравнения, как средства художественной выразительности очень многообразная и интересная тема для исследования. А произведение Стивена Кинга представляет особый интерес, в виду наличия в нем более 50 сравнений, перевод которых вызывает множество трудностей у переводчиков. Следует также отметить, что при передаче сравнений с английского на русский язык, переводчики не придерживаются определенной переводческой стратегии. Переводчики используют различные трансформации, которые помогают сохранить образное значение. Выбор трансформаций обусловлен наличием лексических соответствий в переводящем языке, литературной нормой русского языка, может быть субъективным выбором переводчика, а также может быть обусловлен контекстом.

$$
* * *
$$

1. Арнольд, передачиИ. В. Стилистика себя современного грусти английского частотности языка. : stood учебник нкретизация для существующую вузов / И. В. Арнольд переводчик М.: второй Флинта, замена Наука, 2002. - 384 с.

2. Виноградов, В.С. Введение в переводоведение (общие и лексические вопросы) / В.С. Виноградов. М.: Издательство института общего среднего образования РАО, 2001. - 224 с.

3. Гальперин, вместо И. Р. Стилистика shower английского безопасности языка / И.Р. Гальперин. Москва, 2004. - 321 с.

4. Гарбовский Н. К. Теория перевода: Учебник для студ. высш. учеб.заведений. - М.: Издательство Московского университета, 2004. - 542 с.

5. Казакова, Т. А. Практические основы перевода. English - Russian. Учебное пособие. / Т. А. Казакова. - СПб.: Лениздат; Издательство «Союз», 2002. - 320 с.

6. Комиссаров, В. Н. Общая теория перевода. Проблемы переводоведении в освещении зарубежных ученых. Учебное пособие. / В. Н. Комиссаров. - М.: ЧеРо, 1999. - 134 с.

7. Солодуб, Ю.П. Теория и практика художественного перевода: учеб. пособие для студ. лингв, фак. высш. учеб. заведений / Ю. П. Солодуб. - М.: Издательский центр «Академия», 2005. - 304 с.

8. King, Stephen. The Green mile. / Stephan King. - M: Pocket Books, 1996. - 544 c.

9. Кинг, С. Зеленая миля. /С. Кинг. - Перевод М.В. Опалева. - М: Аст-Пресс, 1997. -382 с.

10. Кинг, С. Зеленая миля. /С. Кинг. - Перевод В.А.Вебера. - М: Аст-Пресс, 2015. -384 с. 